\title{
TERRITÓRIO SAGRADO: EXÍLIO, DIÁSPORA E RECONQUISTA KRENAK NO VALE DO RIO DOCE, RESPLENDOR, MG
}

\author{
SACRED TERRITORY: EXILE, DIASPORA AND KRENAK RECONQUEST IN RIO \\ DOCE VALLEY (RESPLENDOR, MINAS GERAIS, BRAZIL)
}
SOL SACRÉ: L'EXIL ET LA RECONQUÊTE DE LA TERRE AU VALLÉE DU RIO
DOCE, (RESPLENDOR, MG, BRÉSIL)

Rogério Costa Reis - Faculdade Castelo Branco - Colatina - Espírito Santo - Brasil

rogerio.costa.reis@hotmail.com

Patrícia Falco Genovez - Universidade Vale do Rio Doce - Governador Valadares - Minas Gerais - Brasil

patricia.genovez@superig.com.br

\begin{abstract}
Resumo
Os Krenak, remanescentes dos antigos botocudos, passaram por várias investidas governamentais que pretendiam a eliminação ou a civilização dos nativos. As primeiras ações do Estado foram fundamentadas na edição da Carta Régia de 1808, que estabeleceu as Divisões Militares do rio Doce com o intuito de ocupar demograficamente este território e eliminar os botocudos, tidos como um entrave para o crescimento econômico da região. Esta política, iniciada ainda no período colonial e intensificada no Segundo Reinado, não obteve o sucesso pretendido e o vale do rio Doce passou a ter uma ocupação demográfica significativa após a implantação da Estrada de Ferro Vitória-Minas (EFVM), na década de 1910. Este artigo discute a construção do território Krenak, em Resplendor/MG, no vale do rio Doce, tendo como base os exílios, as diásporas e a reconquista, ocorridos entre 1958 e 1997. Abordaremos, por um lado, a ação efetuada pelo extinto Serviço de Proteção ao Índio (SPI) e pela Funai com o objetivo desterritorializar os indígenas. Por outro lado, trataremos o mesmo processo na perspectiva dos indígenas, enfocando os vínculos sagrados estabelecidos com os elementos da natureza e sua influência na constituição de um território sagrado para os Krenak.

Palavras-chave: território sagrado, território Krenak, história Krenak.
\end{abstract}

\section{Abstract}

The indigenous Brazilian group - Krenak - botocudo remnants, survived several government attacks which aim was to exterminate or civilize them. The first State actions were fundamental in the process of editing Carta Regia (1808), by establishing Military Divisions in Rio Doce focusing that territory demographic occupation and the elimination of botocudo people, considered an obstacle to the region economic growth. This policy, starting in Brazilian Colonial time and intensified during the Segundo Reinado (mainly in the XIX Century), did not achieve the intended success and Rio Doce Valley received a meaningful demographic occupation, after VitoriaMinas Railway implantation, in 1910 decade. Having this background as a starting point, this article debates the Krenak territory construction, in Resplendor (Minas Gerais State district), in Rio Doce Valley, considering exiles, diasporas and land reconquest, from 1958 until 1997. It will address SPI (former Governmental Office dealing with indigenous issues: Indian's Protection Service) and Funai actions (today's Governmental Office: Indians' National Foundation) in the process of expropriating those indigenous people. It will also address the same process from the Krenak people's perspective, considering the sacred links established with natural elements and their influence in the construction of a territory sacred to the Krenak.

Key words: sacred territory, Krenak territory, Krenak history. 
Résumé

Le peuple Krenak descendant de les Botocudo, souffert de tentatives de extinction ou de civilization au cours de I'histoire. La Carta Regia - document officiel de déclaration de guerre - de 1808 établit d'una parte la situation belliqueuse et d'autre la division du territoire de la valée de le Rio Doce avec des Divisions Militaires (casernes et quartier d'habitation des soldats). Le but a été occuper ce territoire et démographiquement éliminer les indiens que ont été considéré alors comme un obstacle à la croissance économique de la région. Ce genre de relation du gouvernement avec les indiens a commencé dans la période coloniale (XVle et XVIle siècles) s'intensifiée dans le Second Empire (XIXe siècle), mais n'a pas obtenu le succès attendu. Une occupation démographique important du valée du Rio Doce a commencé seulement après la construction de la voie ferrée Vitória-Minas (EFVM), dans les premiers années du XXe siécle. Cet essai analyse la construction symbolique territoire Krenak dans la voisinage de la ville de Resplendor dans la valée du Rio Doce (Minas Gerais, Brésil). Ces indiens ont été exilés, ont vecu des diaspora et de la reprise du leurs terres, entre les années1958 et 1997. D'une parte ils ont souffert d'abord la protection du Service de Protection des Indiens (SPI) et ensuite les tentatives de déterritorialization achevées par la Funai. Ici on analyse ce processus dans la perspective des peuples autochtones. Les liens établis avec des éléments sacrés (nature) et son influence sur la création d'un territoire aussi sacré pour Krenak sont les poins les plus importants.

Mots cles: territoire sacré, territoire Krenak, Krenak, histoire.

\section{Introdução}

A partir de 1808, com a transferência da Corte Portuguesa para o Brasil, o Estado estabeleceu inúmeras investidas contra os Krenak, à eliminação ou a civilização dos nativos. A primeira ação do governo português foi a edição da Carta Régia de 1808 que estabelecia as Divisões Militares do rio Doce visando a ocupar demograficamente este território e eliminar os nativos, tidos como um entrave para o crescimento econômico da região.

Esta política, iniciada ainda no período colonial e intensificada no Segundo Reinado, não obteve o sucesso pretendido e o vale do rio Doce passou a ter uma ocupação demográfica significativa após a implantação da Estrada de Ferro Vitória-Minas (EFVM), na década de 1910. Com o aumento populacional da região, os Krenak veem seu território ocupado por fazendeiros com o aval do extinto Serviço de Proteção ao Índio (SPI). A ocupação acabou levando o órgão estatal a promover a retirada dos Krenak de suas terras, o que fez com que passassem a viver em outro espaço juntamente com outras etnias.

Assim, nossa perspectiva é a de analisar a relação simbólica, configurada desde longa data, existente entre os Krenak, seu território e, principalmente, como este grupo conseguiu transformar este fator em um trunfo na luta pela delimitação de sua atual Reserva. Para tal tarefa, partiremos de alguns pressupostos de Haesbaert (2005), do qual abstraímos as concepções fundamentais de múltiplos territórios para fundamentação da análise dos momentos de exílio vivido pelos Krenak. Propomos, portanto, 
discutir as concepções de território destacadas por Haesbaert (2006) no livro O Mito da desterritorialização para, a partir daí, discutirmos a efetividade da desterritorialização promovida pelo SPI e, consequentemente, a multiterritorialidade resultante de todo o processo.

\section{RESERVA INDÍGENA KRENAK}

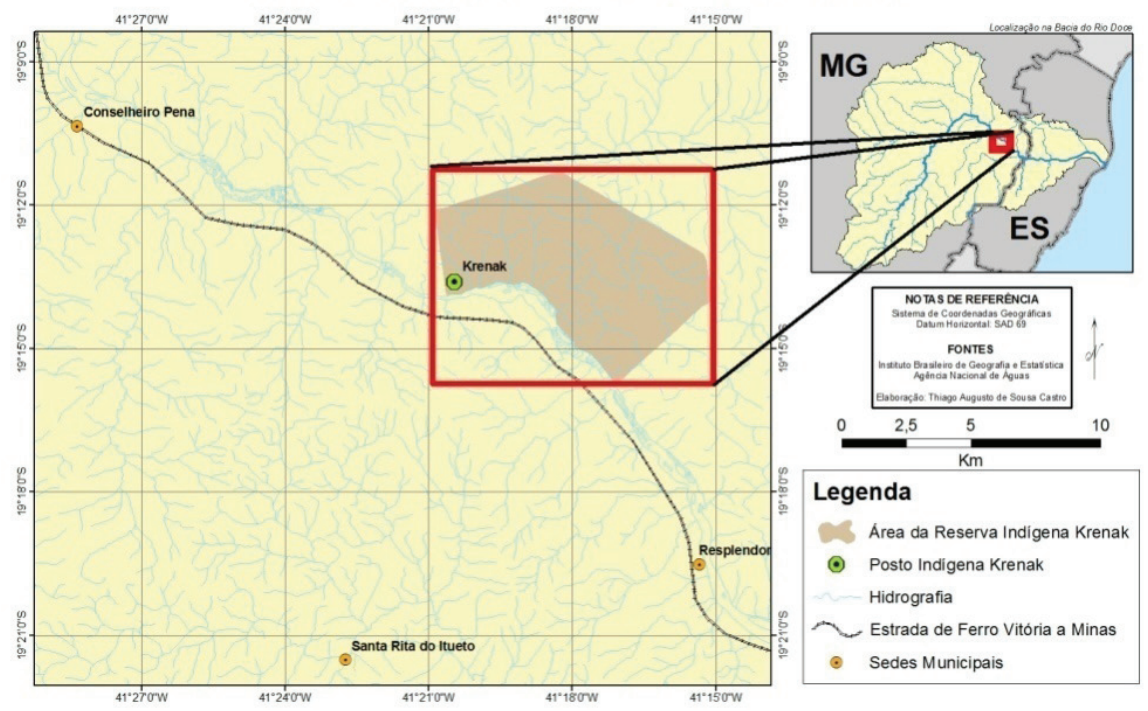

Inicialmente, apesar da amplitude e da complexidade do conceito de território, Haesbaert (2006, p. 40) estabelece em sua análise três aspectos da construção territorial. O autor apresenta o território buscando enquadrá-lo em suas concepções política, cultural e econômica. Além disso, destaca a relação de poder como substrato fundamental para a construção do território. Partindo desta visão, o autor enfatiza que o poder não é um objeto ou coisa, mas que se estabelece a partir de uma relação, ainda que de forma desigual. Assim, o poder não possui um centro de onde emana de forma totalitária, como muitos o entendem apenas com a dimensão do poder do Estado. Esta análise deve ser entendida para além da dimensão do Estado, buscando uma inserção do poder na construção social, na vivência territorial de um determinado grupo em sua apropriação simbólica (Haesbaert, 2006, p. 83 e 84). Interessa-nos mais de perto esta dimensão simbólica, em que um determinado grupo, a partir de sua vivência terri- 
torial, acaba dotando um determinado espaço de significados. Essa dinâmica pode ser vista a partir dos espaços sagrados, da representação que elementos da natureza podem assumir para um determinado grupo. Essa construção simbólica, que também nos remete a uma dimensão de poder, está na base de todo território que, segundo Haesbaert (2005), possui sempre uma dimensão simbólica e outra funcional.

Essa dimensão funcional, constituída de fato como uma característica econômica, encontra-se na construção do território como fator de base para a subsistência de um grupo. No caso específico do território Krenak, a concepção funcional acaba se integrando de forma muito intensa com a dimensão simbólica do território, principalmente no que se refere aos espaços sagrados, que muitas vezes englobam as duas dimensões. O rio Doce, por exemplo, ente sagrado para os Krenak, também assume uma posição funcional, como mantenedor da pesca, que é integrada à subsistência do povo.

Partindo da dimensão do poder, uma abordagem sobre o território com conotação importante para estabelecermos um vínculo com o objetivo central deste artigo se baseia no trabalho de Marcelo Lopes de Souza. Para o autor, o território é compreendido como um campo de força ou como uma rede de relações sociais a partir dos quais se definem uma alteridade: “a diferença entre 'nós' (o grupo, os membros da coletividade ou 'comunidade', os insiders) e os 'outros' (os de fora, os estranhos, os outsiders)” (Souza, 2001, p. 86). Nessa concepção, o território ultrapassa a percepção do Estado Nacional e pode ser configurado como uma rua ou como o conjunto dos países-membros da Organização do Tratado do Atlântico Norte (OTAN) (Souza, 2001, p. 81).

Assim, o que define o território são as relações de poder concentradas no processo de delimitação do espaço. Esta ação se dá, quase sempre em grupo, quando este estabelece Não obra de Souza com esta data. Nas REFS aparece obra de 1995) a ação de poder sobre este território. São os "de dentro", os "insiders". Esta ação se desenvolve em uma concepção dialética em relação aos outros, os "de fora" ou os "outsiders", em uma referência direta ao pensamento de Marcelo Lopes de Souza, citado anteriormente.

Outro conceito que é importante para nossa análise é o de territorialidade, compreendida como uma estratégia que perpassa e ultrapassa a dimensão do poder, pois compreende o conjunto de relações que se desencadeiam na complexidade do território. Aí estão inseridas todas as manifestações humanas que incluem o saber, o fazer, as disputas, os equilíbrios, os símbolos, as representações coletivas, políticas e sociais. 
Retornando os pressupostos de Haesbaert (2006), o autor trata o fenômeno da territorialidade como um conceito simbólico cultural, o que a nosso ver possui extremo significado para a análise da territorialidade que propomos estudar. Segundo ele, "territorialidade, além da acepção genérica ou sentido lato, onde é vista como a simples 'qualidade de ser território’ é muitas vezes concebida em um sentido estrito como a dimensão simbólica do território" (Haesbaert, 2006, p. 73-74). Nesse aspecto, a territorialidade está intimamente ligada ao modo como as pessoas utilizam a terra, como elas próprias se organizam no espaço e como atribuem significados ao lugar.

Assim, podemos definir com base nos autores citados que, em nosso enfoque, a territorialidade se configura sempre como uma relação baseada, entre outros atributos, em valores simbólicos e/ou nas relações e ações que os indivíduos desenvolvem no território. O estabelecimento de ações econômicas sobre o espaço (no caso dos antigos Botocudos, a caça, a pesca e a coleta), a ação de enterrar os mortos (ação concreta e simbólica), criando assim um referencial simbólico ligado ao lugar em questão, são ações que constituem a territorialidade de um grupo em relação ao seu território. Para uma melhor compreensão desses aspectos simbólicos consideramos significativa uma breve retomada da trajetória dos Botocudos no intuito de rastrear, em seu processo histórico, as configurações que perpassaram a cosmologia da etnia Krenak, nos vários momentos de exílio, diáspora e reconquista de seu território.

\section{Elementos da constituição territorial dos Botocudo no vale do rio Doce}

Os Botocudos, conhecidos assim devido ao uso de adornos labiais e auriculares, ocupavam os vales dos rios Doce, Mucuri e Jequitinhonha. Apesar de o termo "botocudo" caracterizar uma concepção pejorativa dos europeus em relação aos povos nativos, a maior parte da literatura referente ao assunto utiliza esta expressão para classificar este povo.

Os então chamados Botocudos se subdividiam em pequenos grupos, de 60 a 200 indivíduos, que possuíam características culturais semelhantes, apesar das delimitações territoriais serem bem definidas, conforme aponta Espíndola (2005), ao destacar os relatórios das Divisões Militares do Rio Doce que mencionam o estabelecimento das divisões territoriais entre as principais nações de Botocudos. Na parte meridional do rio Doce 
habitavam os Graknun (também conhecidos como Kraknum), Nakarene (Nakrehé), Pejaurum (Kejaurin) e os Etwét. Na parte Setentrional, sentido norte-sul, estavam os territórios de caça e coleta dos Naknenuck, Jiporok, Kumakã, entre outros. O sul da Bahia (nos vales do Salitre e do Prado) era habitado pelos Guerém.

Dessa forma, cada nação ocupava territórios delimitados, com espaços vazios de separação entre eles, nos quais outras tribos se estabeleciam, principalmente as de língua Maxacali. As nações mais numerosas e com territórios mais extensos eram os Naknenuck, Jiporok e Nakrehé. Este último dominava a margem sul do rio Doce, locomovendo-se no sentido Leste-Oeste (Espíndola, 2006). Entre estes grupos havia pequenas variações dialetais, embora o tronco linguístico fosse o mesmo. As divergências políticas, que eram muitas, frequentemente os levavam a guerrear entre si (Mattos, 1996; Paraíso, 1992; Caldeira, 2009).

As considerações sobre a delimitação do território entre os Botocudos se fazem fundamentalmente com base na organização social de cada grupo e no poder que estabeleciam no uso de um determinado espaço, transformando-o em território. Nesse sentido, o termo "território" assume uma concepção funcional combinada com uma expressiva carga simbólica (Haesbaert, 2006), em que a vivência do grupo, em articulação com o território, se fundamenta no poder estabelecido a partir do modo de vida de cada grupo (Naknenuck, Jiporok, Nkrehé, dentre outros). Sobre este aspecto, o etnógrafo russo Henri Manizer, durante o período em que teve contato como os Botocudos do rio Doce, em especial os Krenak, relatou aspectos que remetem à utilização do território. A delimitação territorial para ele assume uma característica bastante funcional no seu uso, ressaltando as atividades de subsistência como a caça e a pesca.

Os Krenak vivem em um território que eles encaram como sua propriedade inviolável. O direito natural é muito desenvolvido entre eles e seus territórios são separados daqueles de outros grupos vizinhos por limites naturais, colinas ou montanhas, que eles respeitam em suas caçadas (ao ponto mesmo de não aceitar, quando localizados no posto de pancas, os produtos de caça morta a tiros em territórios que eles não consideram seus). (Manizer apud Mattos, 1996, p. 60)

Em outras palavras, o território dos antigos Botocudos se constituía dentro de um caráter funcional, estabelecendo a caça, a pesca, a coleta, 
enfim, o modo de subsistência de cada grupo. Por outro lado, esta mesma funcionalidade acabava assumindo um postulado extremamente simbólico, em que os rios, as montanhas, a floresta serviam de referência para o estabelecimento dos limites territoriais de cada subgrupo, conforme mencionado acima. Esta relação (simbólica e funcional) está no cerne de toda dinâmica territorial que pretendemos abarcar.

Conforme mencionado, os grupos botocudos eram compostos por números reduzidos de indivíduos. Tal fato contribuía para os deslocamentos de seus membros dentro dos territórios estabelecidos. A cisão do grupo, dando origem a uma nova formação, era algo muito comum entre eles. Esta subdivisão entre os grupos ocorria regularmente e sempre em razão do crescimento do número de famílias ou de conflitos internos. Cada novo subgrupo formado instituía seu nome, usando como referência acidentes geográficos ou o nome do cacique que liderava a dissidência (Paraíso, 1992, p. 428; Espindola, 2005, p. 137).

Dessa forma, este modelo de organização social produz uma territorialidade bastante peculiar. Como os grupos estão em constante movimento, tanto no sentido do "ir e vir" em virtude do nomadismo, como no sentido das dissidências grupais, o processo de territorialização torna-se muito dinâmico, com significações muito fortes e uma necessidade de manutenção dos territórios constituídos, evitando a ocupação dos mesmos por outros grupos. Este processo de territorialização, certamente, não passa apenas por questões de caráter econômico (como o fato de o espaço utilizado para a caça delimitar o território do grupo), ou nos dizeres de Haesbaert, pela questão do tipo funcional de território. Outros fatores simbólicos foram fundamentais nesta constituição territorial. Os rios, córregos, as montanhas, pontos específicos da floresta, como uma árvore ou uma gruta ganhavam significados incorporados à percepção do território que até hoje estão presentes entre os Krenak. O rio Doce, por exemplo, conhecido na língua Krenak como Watu, é um ente sagrado para este povo. Sobre esse aspecto, Zeny Rosendahl nos fornece subsídios significativos, ao afirmar que "os povos têm atribuído sacralidade a diferentes objetos como árvores sagradas, pedras, grutas com poderes milagrosos, ou fontes que curam" (Rosendahl, 2002, p. 68). Cabe, portanto, evidenciar que a construção do território pelos antigos Botocudos não estava vinculada apenas a sua função de subsistência; mas havia outros elementos que se tornaram essenciais para a construção da identidade deste povo na relação com seu território. 
A ação governamental e a dispersão dos Krenak: a constituição de (multi)territórios

Os Krenak compunham um dos grupos de botocudos e ocupavam o Vale do rio Doce. Segundo Soares (1992) e Paraíso (2002), a formação dos Krenak se deu a partir de uma cisão dentro do grupo dos Gutkrak, na região do rio Pancas, por volta de 1918, por ocasião dos primeiros contatos com o SPI . O órgão mantinha um Posto de atração indígena denominado "Posto Pancas", na localidade onde se situa atualmente a cidade de Pancas no Estado do Espírito Santo. O intuito do SPI era transformar o Posto de Pancas em um local para onde deveriam ser atraídos todos os grupos indígenas da região (Corrêa, 2003, p. 90).

Durante a tentativa dos agentes desse órgão de atrair os Gutkrak para aquele posto, houve descontentamento entre parte dos integrantes do grupo que se dividiram e deram origem a uma nova formação (Soares, 1992, p. 85). Paraíso (2002) destaca que, a partir desta cisão dentro do grupo dos Gutkrak, o capitão Krenak, já estabelecido na aldeia do Quijeme Brek, nas margens do rio Eme, ${ }^{1}$ continuou se recusando a estabelecer contatos com os agentes do SPI. Tal contato só foi efetivado após o massacre do Kuparak, em 1923, com o filho de Krenak, Muin, o qual determinou a localização do posto de atração do Eme (Soares, 1992, p. 111).

A manutenção deste posto não fazia parte dos planos do Serviço de Proteção ao Índio, que tinha a intenção de transferir os Krenak para o Posto Indígena de Pancas, no Espírito Santo (Paraíso, 2002, p. 420). Com a resistência dos Krenak, em 1918, engenheiros a serviço do SPI começam a demarcar terras no ribeirão do Eme. O governo do estado de Minas Gerais faz uma doação de 2.000 hectares de terra e determina a criação de uma colônia para os índios Pojixá e Krenak. No mesmo ano, a Assembleia Legislativa do Estado amplia a área para 4.000 hectares visando à inclusão de outras etnias naquela colônia indígena (Soares, 1992, p. 108; Mattos, 1996, p. 81; Paraíso, 2002, p. 420).

No intuito de proporcionar o desenvolvimento da agricultura no vale do rio Doce, o Serviço de Proteção ao Índio, realizou o arrendamento destas terras ocupadas pelos indígenas a fazendeiros e sitiantes que viviam no entorno deste espaço. Esta prática tinha o intuito de transformar os índios em trabalhadores nacionais, através da agricultura. O objetivo era inserir agricultores nas terras indígenas visando "à fabricação de cidadãos” (Corrêa, 2003, p. 93). Contudo, este modelo de ocupação das terras indígenas acabou provocando uma mudança no padrão de ocupação do 
espaço pelos indígenas. Os fazendeiros acabaram estabelecendo o domínio sobre grande parte das terras utilizadas pelos Krenak, pressionando para que os Krenak fossem retirados das terras do Vale do rio Doce, de modo a desobstruir essas terras para as práticas agrícolas.

A primeira transferência se deu em 1958 quando os Krenak são retirados de forma violenta de suas terras pelos agentes do SPI e levados para as terras dos índios Maxacali, no município de Santa Helena de Minas. Este período de exílio dura aproximadamente dois anos e possui uma presença muito marcante na memória dos Krenak. Para os Krenak, as maiores dificuldades enfrentadas durante o exílio eram a falta de rios para a pesca, o clima frio, as péssimas condições de moradia, a terra esgotada pela agricultura e a hostilidade dos Maxacali contra os Krenak. Essas questões fizeram com que os Krenak reivindicassem junto aos funcionários do SPI o retorno à sua terra natal. Como os funcionários do SPI não atenderam às solicitações dos Krenak, eles voltaram de forma épica: fizeram o trajeto a pé entre o município de Santa Helena de Minas e Governador Valadares, numa viagem que teve uma duração média de três meses (Soares, 1992, p. 133; Mattos, 1996, p. 100; Paraíso, 2002, p. 421).

Este retorno é percebido pelos Krenak como uma verdadeira epopeia e possui um simbolismo muito grande na mentalidade do grupo. De fato, o retorno é a prova de um vínculo territorial que nunca se desfez. Em outras palavras, o sentimento de pertencimento ao rio, à floresta, à pedra dos Sete Salões, aos eventos religiosos que devem ser realizados no território Krenak, foi mais forte que a imposição do SPI de viverem em outras terras. Vale destacar que durante esse período de transferência, há um pequeno grupo que recusa o exílio em terras Maxacali e consegue se refugiar em uma ilha no rio Doce, permanecendo aí durante todo período de exílio dos demais Krenak. Essa permanência de alguns Krenak no Vale do rio Doce acabou se transformando em uma referência para o retorno daqueles que se encontravam no exílio (Soares, 1992, p. 131; Mattos, 1996, p. 100, Paraíso, 2002, p. 421; Espíndola, 2006).

Contudo, neste momento do retorno, ocorre uma dispersão entre os índios. O SPI acaba dando destinos diferentes àqueles que saíram das terras Maxacali. Muitos são encaminhados de trem para as terras Krenak no município de Resplendor, MG, outros são encaminhados pelo SPI para outras terras indígenas, dentre elas o Posto Indígena Bananal em São Paulo, Posto Indígena Cachoeirinha no Mato Grosso; a grande maioria vai para o Posto Indígena Vanuíre no município de Tupã no interior de São Paulo, 
onde já estavam estabelecidos os Kaingang (Soares, 1992, p. 135; Paraíso, 2002, p. 422; Caldeira, 2009, p. 54).

Os Krenak que chegam a Vanuíre e passam a viver entre os Kaingang não abandonam sua identidade, tampouco esquecem o simbolismo dos elementos existentes nas terras Krenak do município de Resplendor. Em virtude dessa característica, acaba ocorrendo uma reconstrução destes elementos em outras terras, refazendo e ressignificando novas redes sociais, permeadas por relações de poder específicas que permaneciam ligadas simbolicamente à identidade Krenak.

Os Krenak que se estabelecem no Posto Indígena Vanuíre acabam reconstruindo um novo "ser Krenak" nestas terras. A manutenção da língua, da dança, do artesanato, dentre outros elementos da cultura Krenak, foram importantes para a manutenção e reconstrução territorial dessa etnia em terras Kaingang. Porém, o principal fator facilitador dessa construção foram os casamentos interétnicos envolvendo Krenak e Kaingang (Silva, 2009). Os filhos provenientes destas uniões, na maioria das vezes, acabam se identificando com a etnia Krenak, devido à tradição cultural e à coesão que o grupo construiu no território de Vanuíre. Assim, mesmo no exílio, os Krenak acabam constituindo (multi) territórios ao contrário de uma desterritorialização almejada pelo Serviço de Proteção ao Índio. Segundo Haesbaert (2006, p. 341), "no caso de um indivíduo e/ou grupo social mais coeso, podemos dizer que eles constroem seus (multi)territórios integrando, de alguma forma, num mesmo conjunto, sua experiência cultural, econômica e política em relação ao espaço".

Assim, após o primeiro exílio entre os Maxacali, os Krenak acabam sofrendo um segundo momento de desterro. Este sob a gestão da recém-criada Fundação Nacional do Índio (Funai). Novamente, por interesses econômicos, o órgão indigenista promove a retirada dos Krenak, estabelecidos no vale do rio Doce, e os leva para a Fazenda Guarani no município de Carmésia/MG. Neste segundo exílio, que durou oito anos (1972-1980), os Krenak dividiram um mesmo território com os índios Pataxó. Novamente, a relação com outra etnia, a escassez de terras férteis e, principalmente, a distância das terras do rio Doce fizeram com que os Krenak retornassem a sua terra natal.

Ao retornarem, suas terras se encontravam ocupadas por fazendeiros que, naquele momento, possuíam títulos de propriedade emitidos pelo governo de Minas Gerais. Esses títulos davam aos fazendeiros o status de 
proprietários (Soares, 1992), ou seja, na perspectiva do Estado, os Krenak encontravam-se desterritorializados do vale do rio Doce e reterritorializados na Fazenda Guarani. A ação do Estado em transferi-los para outras terras definia esta circunstância. Para os fazendeiros que haviam conquistado a documentação de propriedade dessas terras, os índios eram assunto encerrado. Os proprietários das terras agora eram eles, afinal havia uma garantia do Estado, os títulos emitidos pelo governo. Por outro lado, na perspectiva dos Krenak, essa lógica do Direito não era aplicável já que foram os Kraí (brancos) que os haviam retirado de suas terras. Para o índio, não era um documento que dizia quem era dono, mas sim a vivência com a terra.

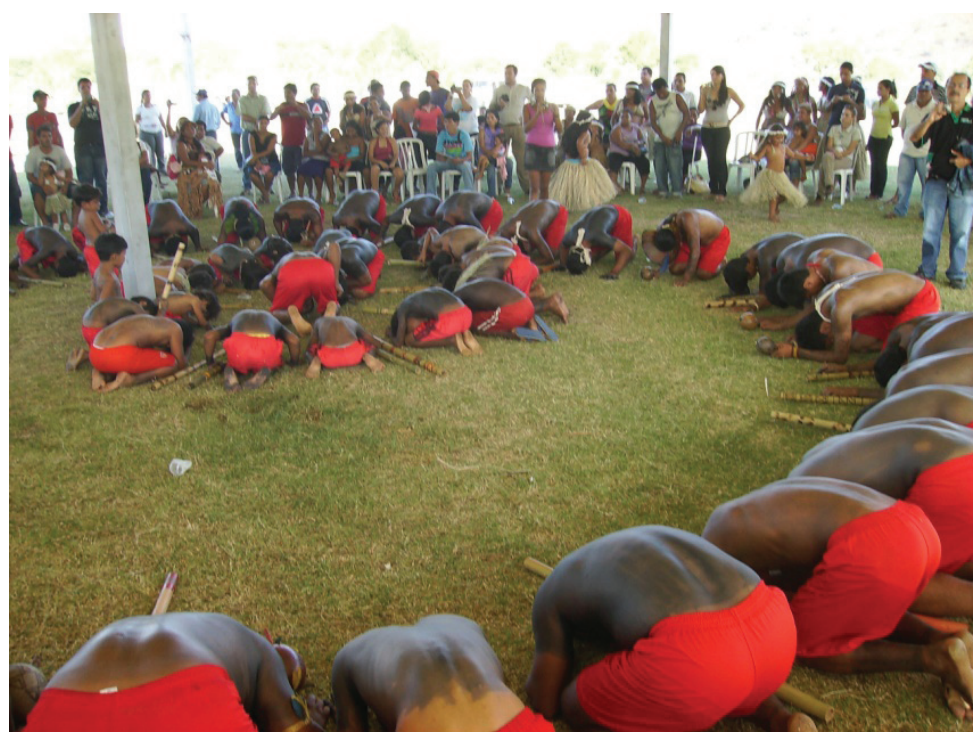

Cerimônia religiosa Krenak

Foto: Dório Costa

Esta dinâmica na produção do espaço acabou produzindo uma sobreposição de territórios. Onde havia um território indígena, foi constituído um território agrícola, entregue a fazendeiros. Tentaremos compreender este fato utilizando, uma análise de Marcelo Lopes de Souza (1995), que, ao analisar diversas formas de território na cidade do Rio de Janeiro, destaca a complexidade territorial presente numa sobreposição de 
diversos territórios, com formas e limites variados. Além disso, as territorialidades existentes são diferentes por conta dos atritos e contradições que envolvem as diversas manifestações de poder (Souza, 2005, p. 94). No caso em questão podemos entender que o mesmo espaço acabou se transformando em dois territórios distintos. Para os Krenak um território simbólico, no qual projetaram seu modo de vida. Para os fazendeiros um território predominantemente econômico.

No caso dos Krenak, há um sentimento muito forte de vinculação à terra. Este sentimento é o que faz com que os Krenak retornem depois de cada exílio. Faz com que lutem pela terra. Mas não se trata de luta por qualquer terra, a luta é pela manutenção das terras do rio Doce. Este sentimento é bem expresso em uma fala de Laurita Krenak a Geralda Soares (1992, p. 149):

A gente vai ficar aqui até morrer. Nosso povo tá todo enterrado aqui. A gente também vai ser. É só a Funai devolver o que é nosso e o que ficou na Fazenda Guarani, que a gente começa tudo de novo. Se eles não ajudar a gente, a gente faz casa de capim. Queremos é ficar aqui, mesmo morto, com nossos antepassados, com o Watu, na terra que é da gente.

O depoimento de Laurita destaca de forma contundente três elementos fortes na constituição da territorialidade Krenak que são: os antepassados enterrados no território Krenak, o rio e a terra. Para ela vale mais estar morto e enterrado nas terras Krenak do que vivo e em outro lugar. Esses são os principais trunfos que os Krenak utilizam na luta pela reconquista da terra. Entretanto, este início de caminhada dos Krenak pela reconquista de suas terras é muito difícil. Ao retornarem da Fazenda Guarani, em 1980, assumem apenas uma pequena faixa de terra na margem esquerda do rio Doce, que atingia 120 hectares. Algo irrisório perto dos 4.039,8241 hectares que fazem parte da Reserva atual. Sobreviver com tão pouca terra foi o primeiro desafio dos Krenak naquele momento.

Para tentar reaver toda a extensão da terra ocupada por fazendeiros, a Funai, em 1983, entrou na Justiça Federal com uma Ação Ordinária de Nulidade de Títulos sobre os imóveis rurais localizados nas terras indígenas Krenak. Esse processo teve uma longa duração e se arrastou na Justiça até o ano de 1995, quando a ação foi julgada favorável aos Krenak. Porém, só após dois anos, já em 1997, a Justiça concedeu a posse das terras aos 
Krenak, formalizando a Reserva Indígena Krenak, no Município de Resplendor (Caldeira, 2009, p. 58; Soares, 1992, p. 191; Paraíso, 1989, p. 22). ${ }^{2}$

Atualmente, os Krenak reivindicam a inclusão das terras conhecidas como Parque Estadual dos Sete Salões à atual Reserva Indígena. A fundamentação desse pleito se apoia na sacralidade que os Krenak atribuem às cavernas existentes naquele espaço. Os significados simbólicos desse território para os Krenak são muito intensos e os coloca intimamente vinculados à sua dimensão cosmológica (Baeta, 2007).

Nesse sentido, a luta pela conquista do antigo território Krenak no vale do rio Doce ainda não foi concluída. Os significados que o território assume para esse povo está em um contínuo processo de reconstrução e ressignificação. O diferencial é que os atuais Krenak têm plena consciência dos seus direitos, dos seus valores e dos trunfos que possuem na luta pela manutenção e reconquista do território de seus antepassados.

\section{Considerações finais}

A construção do território é sempre marcada pela dinâmica do poder. Não só o poder estatal, mas o poder em várias dimensões. Desde o micro, como uma casa, até o macro como a União Europeia, por exemplo. O fundamental é que o território está presente em toda forma de organização humana. No nosso enfoque, buscamos compreender como os antigos Botocudos do vale do rio Doce construíram um território fundamentado em um referencial simbólico, sagrado para os membros desse grupo.

Destarte, a territorialidade dos atuais Krenak, remanescentes dos Botocudos, possui significados tão intensos que nem mesmo dois momentos de exílio foram capazes de apagar da memória desse povo os valores atribuídos ao território do vale do rio Doce. Esses significados são tão intensos que nem mesmo a permanência de um grupo no interior de São Paulo, entre os Kaingang, foi suficiente para "desterritorializar" esses Krenak. Muito pelo contrário. Esse grupo conseguiu se afirmar em um território distante, mesmo dividindo o espaço com outra etnia indígena. Os Krenak de Vanuíre foram capazes de construir novos significados em um outro território, tendo como referência os elementos sagrados de sua terra natal.

Assim, podemos considerar que o longo processo pelo qual os Krenak passaram, sobretudo a partir das ações do Estado, não impediu a ma- 
nutenção dos significados atribuídos a seu território. O poder que define o território e, por consequência, a territorialidade, não se encontrava vinculado essencialmente ao Estado, mas perpassava a sacralidade projetada por um determinado grupo. Em outras palavras, a pretensão do Estado de efetivar uma completa desterritorialização dos Krenak acabou provocando a formação de múltiplos territórios. Mesmo distante de sua terra, os Krenak mantiveram uma dada territorialidade e um território simbólico capaz de trazer muitas famílias de volta ao rio Doce. Os retornados demonstram a construção de uma multiterritorialidade capaz de abarcar referências compartilhadas com os vários grupos com que mantiveram contato. Entre aqueles que se reterritorializaram em outras terras, coexistem a referência material do novo território e a do antigo território Krenak, ainda considerado sagrado por todos.

\section{Notas}

1. O rio Eme é um dos afluentes do rio Doce. Nasce no Município de Cuparaque, MG e deságua no município de Resplendor, MG, pela margem esquerda. O rio Eme atravessa toda a extensão da atual Reserva Indígena Krenak.

2. Esta delimitação da Reserva Indígena Krenak teve como referência a determinação feita pelo governo do Estado de Minas Gerais em 1920 que, através do Decreto n. 5.462 de 10 de fevereiro de 1920, estabeleceu a criação de uma área para os índios Krenak com extensão de 4.000 hectares.

\section{Referências}

BAETA, Alenice Motta; MATTOS, Isabel Missagia de. A serra da onça e os índios do Rio Doce: Uma perspectiva etnoarqueológica e patrimonial. Habitus, Goiânia, v. 5, n. 1, p. 39-62, jan./jun. 2007.

CALDEIRA, Vanessa. História de Botocudo: o povo Krenak na região do Vale do Rio Doce. In: REZENDE, Marcos. ÁLVAREZ, Ricardo (Orgs.). Era tudo mata: o processo de colonização do Médio Rio Doce e a formação dos municípios de Aimorés, Itueta e Resplendor. Belo Horizonte, MG: Consórcio da Hidrelétrica de Aimorés, 2009. p. 42-61.

CORRÊA, José Gabriel Silveira. Política Indigenista, tutela e deslocamento de populações: A trajetória histórica dos Krenak sob a gestão do Serviço de Proteção aos Índios. Arquivos do Museu Nacional, Rio de Janeiro, v. 61, n. 2, p. 89-105, abr./ jun., 2003.

ESPINDOLA, Haruf Salmen. Sertão do Rio Doce. Bauru, SP: Edusc, 2005.

ESPINDOLA, Haruf Salmen Territorialidade em Minas Gerais durante a crise do sistema colonial. III Encontro da ANPPAS: Brasília, 2006. 
HAESBAERT, Rogério. Da desterritorialização à multiterritorialidade. Anais do X encontro de Geógrafos da América Latina. São Paulo: Ed. USP, 2005. p. 6774-6792.

HAESBAERT, Rogério. O mito da desterritorialização: do "fim dos territórios" à multiterritorialidade. 2. ed. Rio de Janeiro: Bertrand Brasil, 2006.

KRENAK, Itamar de Souza Ferreira. Uatu Hoom. Belo Horizonte: Faculdade de Letras da UFMG, Cipó Voador, 2009.

MATTOS, Izabel Missagia de. Borum, Bugre, Kraí: constituição social da identidade e memória étnica Krenak. Dissertação (Mestrado) - Universidade Federal de Minas Gerais, Belo Horizonte, MG, 1996.

ROSENDAHL, Zeny. Espaço e religião: uma abordagem geográfica. 2. ed. Rio de Janeiro: Ed. UERJ, NEPEC, 2002.

SOUZA, Marcelo José Lopes de. O território: sobre espaço e poder, autonomia e desenvolvimento. In: CASTRO, Iná Elias de et al. Geografia: conceitos e temas. Rio de Janeiro: Bertrand Brasil, 2001. p. 77-116.

PARAÍSO, Maria Hilda Baqueiro. Laudo Antropológico Pericial Relativo a Carta de Ordem $n^{\circ}$ 89.1782-0 Oriunda do Supremo Tribunal Federal e Relativo a Área Krenak. Universidade Federal da Bahia: 1989.

PARAÍSO, Maria Hilda Baqueiro. Os Botocudos e sua trajetória histórica. In. CARNEIRO DA CUNHA, Manuela (Org.). História dos Índios no Brasil. São Paulo: Companhia das Letras, Secretaria Municipal de Cultura, FAPESP, 1992. p. 413-430.

SOARES, Geralda Chaves. Os Borun do Watu - os índios do Rio Doce. Contagem: CEDEFES, 1992.

SILVA, Daniela Araújo. Diáspora Borum: Índios Krenak no Estado de São Paulo (1937-2008). Dissertação (Mestrado em História) - Universidade Estadual Paulista, Assis, SP, 2009.

Rogério Costa Reis - Possui Graduação em História pela Faculdade de Filosofia, Ciências e Letras de Colatina, mestrado em Gestão Integrada do Território pela Universidade do Vale do Rio Doce e Pós-Graduação Latusensu em Ensino Superior e Desenvolvimento Regional, pela mesma Universidade. Atualmente é professor na Faculdade Castelo Branco.

Patrícia Falco Genovez - Possui graduação em História pela Universidade Federal de Juiz de Fora, mestrado em História pela Universidade Federal Fluminense e doutorado pela mesma Universidade. Atualmente é professora titular da Universidade Vale do Rio Doce.

Recebido para publicação em 18 de outubro de 2012 Aceito para publicação em 21 de janeiro de 2013 